\title{
PREVALENCE AND ETIOLOGY OF DERMATOMYCOSES IN RAJSHAHI,
} BANGLADESH

\author{
Farzana Ashrafi Neela \\ Department of Botany, University of Rajshahi, Rajshahi 6205, Bangladesh
}

\begin{abstract}
Dearmatomycoses are very common infections caused mainly by dermatophytes. A total of 1186 patients ranging from 1-60 years of age were surveyed for dermatomycotic infections in Rajshahi, Bangladesh. Specimens for mycological investigations were confirmed by microscopic examinations in 817 cases and the causative agents were isolated and cultured in 70 positive cases. The highest prevalence of dermatomycosis was of Tinea corporis (63\%) followed by T. pedies (15\%), T. capitis (12\%) and T. unguium (8\%). Trichophyton and Microsporum were the major etiological agents followed by Epidermophyton. This study also showed that there is a great variation in the severity of different types of dermatomycoses at different months of the year.
\end{abstract}

Key words: Dermatophytes, dermatomycoses, Tinea

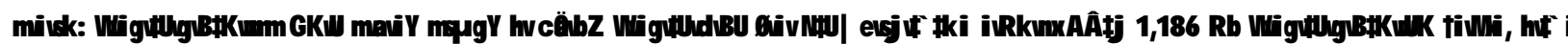

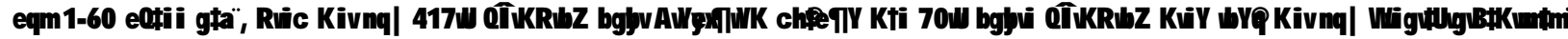

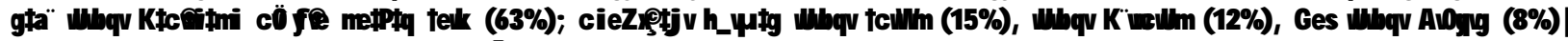

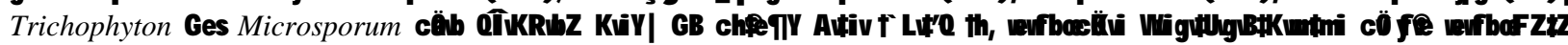
e $\mathrm{x} K \mathrm{~K}$ v

\section{Introduction}

The dermatophytes are fungi which cause diseases of the skin of human, animals or both. They parasitize keratinized tissues, including nails, hair and stratum corneum of the skin, and cause dermatomycoses (Weitzman and Summerbell 1995). The clinical types of dermatomycoses are called tineas by the members of medical profession. Traditionally, tinea infections have been named by anatomic location of the body, such as $\mathrm{T}$. capitis for ringworm of the scalp, $T$. corporis for ringworm of the body, and $\mathrm{T}$. pedis for ringworm of the foot. The dermatophytic groups are typically Hyphomycetes with perfect stage in the Gymnoascaceae. These fungi have frequently been treated as special group the 'Dermatophytes' or Ringworm fungi or tinea. Dermatophytes are cosmopolitan, and occur widely in soil and other keratin containing substrate such as bird's nest and thus, the soil serves as a source of infection of tinea (Ainsworth 1971; Beneke and Rogers 1980).

Untold numbers of people world-wide suffer from these infections with high humid environment. Sex, race and occupation have little recognized differential influence upon the frequency of these infections. Children are mostly affected by dermatomycoses before and during puberty (Elewski 1996). It is caused by a variety of zoophilic, anthropophilic and geophilic dermatophytes of the genera Microsporum, Epidermophyton and Trichophyton ((Weitzman and Summerbell 1995).

The prevalence of dermatomycoses or tinea infections have been studied in different parts of the world (Devliotou et al. 2000; Metin et al. 2001; Akpolat et al. 2005). The relative occurrence of the etiologic agents of these infections varies from country to country and from one climatic region to another (De Vrocy 1985; Ayadi et al. 1993; Korstanje et al. 1995). In tropical countries, a warm and humid climate, crowded living and poor sanitary conditions all promote the spread of these infections (Abdel et al. 1995). Only a few research studies are available on dermatomycoses in Bangladesh (Neela and Alam 2000). The present study is aimed at detecting the prevalence of dermatomycoses infection and etiological agent in Rajshahi, Bangladesh.

\section{Materials and methods}

Sample selection: A total of 1186 patients having age range of 1-60 years suspected to have dermatomycotic infections were randomly selected from outdoor patients of the Skin and Venereal Disease Section of the Rajshahi Medical College Hospital (RMCH), Bangladesh, from July 
1996 to June 1997, covering all the seasons of a year. Questionnaires and physical observations were used to obtain information on duration of the lesion, clinical picture, prior therapy as well as demographic data such as age, sex, nationality and family status of the respondents. The final selected culture positive for this study consisted of 817 patients.

Sample collection: Samples were collected from skin, hair and nail using a sterile scalpel blade following cleaning of the affected sites with $70 \%$ alcohol. The scrapings were collected on a piece of sterile paper. The samples were divided into two portions: one for microscopic examination and the other for culture. The collected samples were transported to the laboratory within 2 hours for microscopic and cultural analysis.

\section{Sample processing}

Direct microscopic examination: Direct microscopic examination of scales and broken-off hairs placed on a microscope slide with one or two drops of $10-20 \%$ potassium hydroxide $(\mathrm{KOH})$ and a cover slip was performed. The sample was warmed for 5 minutes over a flame as described by Behl (1990). Each treated slide was then carefully examined under low $(\times 10)$ and high $(\times 40)$ power objective for the presence of hyphae and/or conidia.

Fungal culture: Each scraping was cultured into Sabouraud dextrose agar (Ajello et al. 1996). The plates or slants were incubated at $28^{\circ} \mathrm{C}$ for up to 4 weeks and examined at 2 to 3 days intervals for fungal growth. Fungal isolates were sub-cultured onto plates of Sabouraud's agar. The isolates were examined visually and microscopically for morphology of the fungi using lactophenol cotton blue by slide culture technique. The dermatophytes were confirmed by dermatophyte test medium, incubated at $30^{\circ} \mathrm{C}$ for 14 days. Genus identification was based on the presence or absence of macro- and microconidia, their shape, and their distribution along the hyphae (Beneki and Rogers 1980).

\section{Results and Discussion}

Of 1186 patients, diagnosis of 817 cases was confirmed by microscopic examinations, and the causative agents were isolated in 70 cases. From the total number of isolates identified, dermatophytes were the most prevalent (Fig. 1). The highest prevalent of dermatophytic infection was $\mathrm{T}$. corporis (63\%), followed by $\mathrm{T}$. pedies $(15 \%)$, T. capitis (12\%) and T. unguium (8\%). Three genera identified from the isolates were Microsporum, Epidermophyton and Trichophyton (Table1). Microsporum was isolated from skin and hair, whereas Epidermophyton from nail only and Trichophyton from skin, nail and hair.

The effect of seasonal weather conditions on the incidence of dermatophytic infections showed that the incidence during each of the months July, August, September and October was evidently higher than that found during each of the months of November, December, January and February. During the months of March, April, May and June the incidence of the infections was somewhat intermediate in position (Fig. 2).

Although dermatomycoses/tinea diseases have worldwide occurrence, its frequency is variable and depends on different climate condition, sex, age, occupational and economical conditions (Neela and Alam 2000). This disease appears to be prevalent in Rajshahi. Accurate assessment of the prevalence of etiologic agents is therefore useful to cure the disease and to prevent its transmission.

Concerning individual types of dermatophytic infection the severity was found the highest in the case of $T$. corporis followed by $\mathrm{T}$. pedis (Fig. 1). These data suggest that the body is always covered with cloths which may help keep the body moist and favorable environment for $\mathrm{T}$. corporis infections. In contrast, $\mathrm{T}$. capitis is predominant in North America (Weitzman and Summerbell 1995). Mabata and Nwajagu (2007) reported that in Nigeria most common incidence of tinea disease is T. capitis and children suffer more than adults (Srejaard 1982). In Bangladesh, the age groups of 16-30 years suffer different types of tinea disease (Neela and Alam 2000). This may be due to the fact that younger people are more physically active and tend to sweat more. Personal hygiene plays an important role for the dissemination of $\mathrm{T}$. corporis. Other tinea diseases are not so prevalent in Rajshahi region.

Table 1. Etiological agents in dermatomycoses infections

\begin{tabular}{|l|l|l|}
\hline \multicolumn{1}{|c|}{$\begin{array}{c}\text { Types of } \\
\text { specimen }\end{array}$} & \multicolumn{1}{c|}{$\begin{array}{c}\text { Clinical name of } \\
\text { the diseases }\end{array}$} & Etiological agents \\
\hline Skin scraping & $\begin{array}{l}\text { Tinea corporis } \\
\text { Tinea pedis }\end{array}$ & $\begin{array}{l}\text { Microsporum } \\
\text { Trichophyton }\end{array}$ \\
Nail clipping & Tinea unguium & $\left\{\begin{array}{l}\text { Epidermophyton } \\
\text { Trichophyton } \\
\text { Microsporum } \\
\text { Trichophyton }\end{array}\right.$ \\
\hline
\end{tabular}


This study also demonstrates that a variety of dermatophytes can cause dermatomycoses. Of the isolated species Trichophyton is the most prevalent isolate followed by Microsporum. Occurrence of these organisms as the major cause of dermatomycoses in Rajshahi has been recorded (Neela and Alam 2000). Oyeka et al. (2003) also reported a similar phenomenon in Nigeria. In our studies Microsporum was isolated from T. corporis and T. capitis. These fungi can be transmitted by infected clothing, towels, bedding and combs. Microsporum is usually acquired from infected pet animals (Shah et al. 1989) that are the reservoir of zoophilic dermatophytes. Trichophyton was isolated from T. pedies, T. unguium and T. capitis. Babel et al. (1989) reported that T. capitis in children was caused by Trichophyton but in adults this genus was more frequently seen as an agent of T. corporis (Bronson et al. 1983). This genus has been reported to have a large number of pathogenic species. The distribution of this genus has been shown to be of similar pattern in connection with Microsporum. Epidermophyton was isolated only from $\mathrm{T}$. unguium. It has been reported to have only two known species to date and only a single species is pathogenic that attacks skin and nails and also is distributed worldwide (Weitzman and Summerbell 1995).

Incidence of dermatomycoses in relation to seasonal weather conditions was shown in Fig. 2. These data clearly show that environmental factors play an important role in increasing and decreasing the incidence of the disease. During the period between July and October, the weather remains relatively warm and humid which would favour the infection, spread and consequently higher incidence of the disease. During the period of November and February the weather remains relatively dry and cold which would decrease the incidence of the disease. Gugnani (1982) attributed the public health problem caused by dermatophytes in Nigeria to the warm humid climate. Oyekaa and Eze (2006) reported that dermatomycoses are public health problem in many countries with high humid environment. Bangladesh, especially Rajshahi, is a warm and humid region; therefore the dermatomycoses are prevalent here.

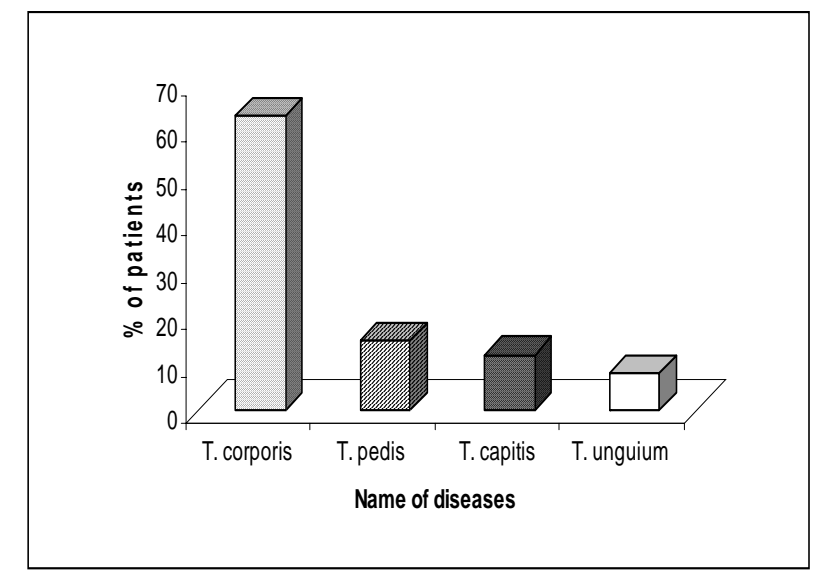

Fig. 1. Prevalence of various types of tinea diseases in Rajshahi

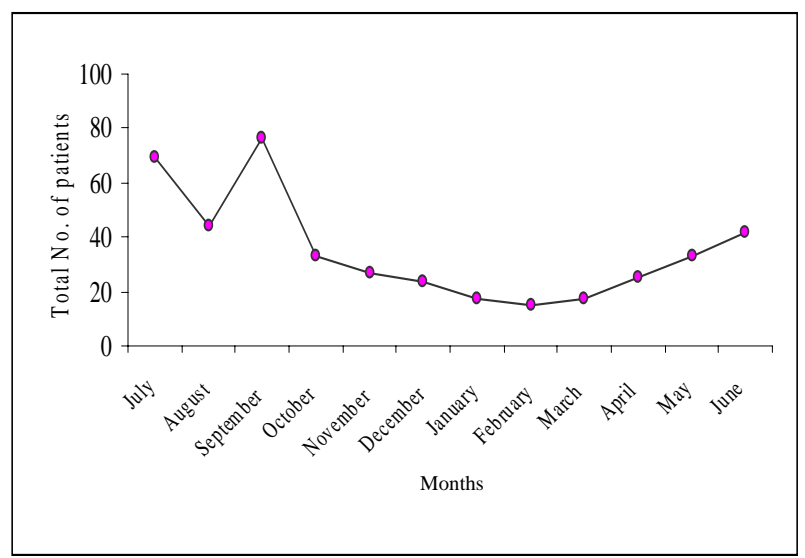

Fig. 2. Incidence of dermatomycotic patients in relation to different months of the year

\section{Conclusion}

The present investigation provides data that are valuable to the determination of dermatomycoses among the population in Rajshahi region. The etiological agents of these diseases could be specifically diagnosed, which could help the physicians to combat the disease with specific drugs. It is obvious that this sort of information is essential for the physician of our country to have correct diagnosis of various types of dermatomycoses that exist here.

Acknowledgement: The author wishes to express sincere thanks and gratitude to Professor M. Shah Alam, Department of Botany, University of Rajshahi, Bangladesh, for his guidance and supervising this work. 


\section{References}

Akpolat NO, Akdeniz S, Elci S, Atmaca S, Ozekinci T. 2005. Tinea capitis in Diyarbakir, Turkey. Mycoses 48, 8-10.

Ainsworth GC. 1971. Dictionary of the Fungi. Commonwealth Mycological Institute, Kew, England. 631 pp.

Ayadi A, Borgi N, Makni F. 1993. Prevalence of Superficial mycoses in an urban ecosystem in Sfax (Tunisa). Bull Soc Path Exot 86, 188-189.

Abdel-Rahman SM, Nahata MC.1997. Treatment of Tinea capitis. Ann Pharmacother 31, 338-348.

Ajello L. Georg LK, Kaplan W, Kaulman L. 1966. Laboratory Manual for Medical Mycology. US Department of Health Education and Welfare, Public Health Service, Communicable Disease Centre, Antlanta, Georgia.

Babel DE, Baughman SA.1989. Evaluation of the adult carrier state in juvenile tinea capitis caused by Trichophyton tonsurans. J Am Acad Dermatol 21, 1209-1212.

Behl PN.1990. Practice of dermatology ( $7^{\text {th }}$ ed.). CBS Publishers and Distributors, Delhi, 895 pp.

Beneke ES, Rogers AL. 1980. Medical Mycology Manual with Human Mycoses Monograph (4 ${ }^{\text {th }}$ Ed.) Burgess Pub. Co. Minneapolis, Minnesota. pp. 59-173.

Bronson DM, Desai DR, Barskey S, McMillen FS. 1983. An epidemic of infection with Trichophyton tonsurans revealed in a 20 year survey of fungal infections in Chicago. J Am Acad Dermatol 8, 322-330.

Devliotou-Panagliotidou D, Koussidou-Eremondi T, Chaidemenos GC, Theodoridou M, Minas A. 2001. Tinea capitis in adults during 1981-95 in Northern Greece. Mycoses 44, 398-404.
De Vrocy C. 1985. Epidemiology of Ringworm (Dermatogphytes). Sem Dermato 14, 185-192.

Eleski B. 1996. Tinea capitis. Dermat Clin 14, 23-31.

Gugnani, HC. 1982. Mycoses are a public health problem in Nigeria. Niger J Microbiol 2, 47-51.

Korstanje MJ, Staats CC. 1995. Fungi infection in the Netherlands: Preventing fungi and pattern of infection. Dermatology 1, 39-42.

Metin A, Suba S, Bozkurt H, Omer C. 2002. Tinea capitis in Van, Turkey. Mycoses 45, 492-495.

Mbata TI, Nwajagu CC. 2007. Dermatophytes and other fungi associated with hair-scalp of nursery and primary school children in Awka, Nigeria. The Internet J Dermat 5(2).

Neela FA, Alam MS. 2000. A survey on tinea disease in Rajshahi, Bangladesh. Univ j zool Rajshahi Univ 19, 73-77.

Oyeka CA, Okoli I. 2003. Isolation of dermatophytic and non dermatophytic fungi from soil in Nigeria. Mycoses 46, 336-338.

Oyeka, CA, Eze II. 2006. Fungal skin infections among prison inmates in Abakaliki, Nigeria. Mycoses, 51, 50-54.

Srejaard E, Onsberg P, Rosman N, Sylvest B. 1982. Dermatophytes and dermatophytosis in Denmark. Mykosen 25, 263-269.

Shah PC, Krajden S, Kane J, Summerbell RC. 1988. Tinea corporis caused by Microsporum canis: report of a nosocomial outbreak. Eur J Epidemiol 4, 33-38.

Weitzman I, Summerbell, RC. 1995. The dermatophytes. Clin Microbiol Rev 8, 240-259. 